\title{
A survey of the diseases of marine turtles in northern Australia. I. Farmed turtles
}

\author{
J. S. Glazebrook, R. S. F. Campbell \\ Graduate School of Tropical Veterinary Science and Agriculture, James Cook University, Townsville, Queensland 4811, \\ Australia
}

\begin{abstract}
A total of 104 farmed turtles (102 Chelonia mydas and 2 Eretmochelys imbricata) were examined for signs of clinical disease. They were obtained from the Torres Strait where they were housed in $250 \mathrm{l}$ fibreglass tanks and $50 \mathrm{l}$ plastic basins and fed a diet of fish by islanders. Altogether, 28 diseases were diagnosed including 12 bacterial, 4 parasitic and 4 nutritional diseases. Less common were those of genetic and environmental origin. Skin lesions due to biting (traumatic ulcerative dermatitis) were almost universal in farmed turtles. They were concentrated on the tips and trailing edges of the front and rear flippers and also on the neck and tail as well as the axillary and inguinal regions. Morbidity and mortality rates of 100 and $30 \%$, respectively, were recorded in the first month of life. Juveniles and yearlings rarely succumbed to the disease. Cultures of lesion material yielded a variety of bacteria viz Vibrio alginolyticus, Pseudomonas fluorescens, Flavobacterium sp., Micrococcus $\mathrm{sp}$. and Bacillus $\mathrm{sp}$. Ulcerative stomatitis was the most important bacterial disease of farmed turtles after traumatic ulcerative dermatitis. It occurred as an epizootic in hatchlings 5 to 8 wk old. A plug of caseopurulent material in the oral cavity was usually the first overt sign of the disease. Debridement sometimes caused bleeding, indicating the presence of false membranes. Obstructive rhinitis and pneumonia were complications of the original condition. Turtles with these diseases showed loss of equilibrium and laboured respiration. Plugs of caseous material were lodged in the trachea/bronchi and/or external nares. Focal pneumonia was characterised by nodular lesions in the apical or medial portion of the lung. Microscopic sections and cultures showed bacteria were mainly responsible. $V$. alginolyticus, Aeromonas hydrophila, Flavobacterium sp. and Pseudomonas sp. were isolated from the upper and lower respiratory tract as well as the oral cavity. Fungal isolates viz Penicillium sp., Paecilomyces sp., Fusarium sp. and Rhodotorula sp. were of secondary importance. Acid fast bacilli (Mycobacterium sp.) were seen in the lungs of 2 farmed turtles but were not isolated. Salmonellosis was diagnosed on only one occasion, when Salmonella enteritidis was isolated from the liver of a juvenile turtle. Eye lesions (keratoconjunctivitis - ulcerative blepharitis) were caused by rubbing against the side of the tank. Adenitis (salt-secreting gland infection) resulted from the introduction of forceps into the duct leading from the posterior orbit. Peritonitis was an extension of ulcerative shell disease. Pseudomonas spp. and Flavobacterium spp. were common to the last 3 diseases. Septicaemia-toxaemia was secondary to chronic bacterial and parasitic infections. $V$. alginolyticus, $A$. hydrophila and Flavobacterium sp. were isolated from the heart blood and caused toxic changes in the heart and kidneys. $V$. alginolyticus was cultured from a case of ulcerative shell disease and osteomyelitis. Gastritis-serositis syndrome was the most important parasitic disease of farmed turtles. Gastric and intestinal ulcers and fibrous adhesions were caused by the migration and encystment of third stage Anisakis sp. larvae from the gut lumen to the pleuro peritoneal cavity. The eggs of cardiovascular flukes (Digenea: Spirorchiidae) were found in farmed turtles. Microscopically, the essential change was that of chronic inflammation. A single species of gastro-intestinal fluke was also found in farmed turtles. Cachetic myopathy was often seen in association with traumatic ulcerative dermatitis and ulcerative stomatitis in farmed turtles. Fibrous osteodystrophy was related to a diet of raw fish and intestinal obstruction was caused by the ingestion of foreign bodies. Lordosis and kyphosis were probably related to the original nest temperature. Genetic defects (albinism and mandibular microagnathia) were rare. There were 2 incidents of poisoning in farmed turtles - due to the accumulation of nitrate from Tridax $\mathrm{sp}$. and contamination of food (fish) with diesel fuel.
\end{abstract}




\section{INTRODUCTION}

In recent years there has been increased interest in the diseases of mariculture-reared green turtles, particularly in the United States. Diseases are of economic importance on farms where a sudden epizootic can result in high mortalities. Rebell et al. (1975) described a herpes virus infection of the skin in hatchlings from the Grand Cayman Island turtle farm where the disease was called 'gray patch disease' after the characteristic skin lesions that appeared at 8 to $12 \mathrm{wk}$. Morbidity and mortality rates of 90 to $100 \%$ and 5 to $20 \%$, respectively, were recorded. Botulism was also prevalent at the time (Smith 1977). Leibovitz et al. (1978) showed that hatchlings 4 to $8 \mathrm{wk}$ old were susceptible to coccidiosis and Jacobson et al. (1979) diagnosed mycotic pneumonia in 29 juvenile turtles with a buoyancy abnormality. Sporotrichium sp., Cladosporium sp. and Paecilomyces sp. were isolated from focal lung lesions in 5 turtles. Recently, Greiner et al. (1980) found flukes (Learedius learedii) in the heart and major vessels of 20 yearling turtles. In Australia, Carr \& Main (1973) identified larval nematodes removed from the body cavities of farmed turtles as Anisakis Type I (simplex or typica),

To add to knowledge in this area, a survey of the diseases of farmed turtles on Torres Strait Islands was carried out between 1977 and 1980 (this study) and for comparative reasons, wild and oceanarium-reared turtles were also examined when the opportunity arose (Glazebrook \& Campbell 1990).

\section{MATERIALS AND METHODS}

Collection of material. The survey period extended from April 1977 to September 1980. Farmed turtles (104 in all) of 2 species viz the green turtle Chelonia mydas and the hawksbill turtle Eretmochelys imbricata were examined for signs of clinical disease.

Between 1973 and 1979 Applied Ecology Pty Ltd operated up to 9 turtle farms (Table 1) in the Torres Strait (Fig. 1). Green turtles from these farms formed the largest single group (102) in the survey. Two hawksbill turtles, from a group of experimental specimens on Yorke Island, were also examined. All diseased turtles were moribund or in extremis when first presented.

Necropsy procedures. Necropsies were performed in the field or at the Graduate School of Tropical Veterinary Science in Townsville. Hatchlings were taken to be 0 to $8 \mathrm{wk}$ old and juveniles 2 to 12 mo old. Turtles more than 12 mo old were referred to as yearlings. All specimens were weighed individually.

Size was determined by measuring the curved length and breadth of the carapace as well as the length of the
Table 1 Geographical location of turtle farms in the Torres Strait

\begin{tabular}{|lrc|}
\hline Island & Coordinates & $\begin{array}{c}\text { Distance from } \\
\text { Thursday Island } \\
\text { (km) }\end{array}$ \\
\hline Badu & $10^{\circ} 07^{\prime} \mathrm{S}, 142^{\circ} 07^{\prime} \mathrm{E}$ & 89.032 \\
Moa & $10^{\circ} 11^{\prime} \mathrm{S}, 142^{\circ} 16^{\prime} \mathrm{E}$ & 64.814 \\
Yam & $9^{\circ} 53^{\prime} \mathrm{S}, 142^{\circ} 45^{\prime} \mathrm{E}$ & 96.296 \\
Sue & $10^{\circ} 12^{\prime} \mathrm{S}, 142^{\circ} 49^{\prime} \mathrm{E}$ & 83.333 \\
Coconut & $10^{\circ} 03^{\prime} \mathrm{S}, 143^{\circ} 05^{\prime} \mathrm{E}$ & 116.666 \\
Yorke & $9^{\circ} 45^{\prime} \mathrm{S}, 143^{\circ} 25^{\prime} \mathrm{E}$ & 164.814 \\
Stephen & $9^{\circ} 31^{\prime} \mathrm{S}, 143^{\circ} 32^{\prime} \mathrm{E}$ & 196.296 \\
Darnley & $9^{\circ} 35^{\prime} \mathrm{S}, 143^{\circ} 47^{\prime} \mathrm{E}$ & 225.925 \\
Murray & $9^{\circ} 56^{\prime} \mathrm{S}, 144^{\circ} 03^{\prime} \mathrm{E}$ & 277.777 \\
\hline
\end{tabular}

plastron; each at its widest point. When required, blood was obtained by a modified heart puncture (after Gandal 1958).

Moribund turtles were euthanised by the intracerebral injection of several $\mathrm{ml}$ of ethanol. To permit a thorough examination of organs inside the body cavity the front flippers and their attendant skeleto-muscular system were displaced anteriorly following disarticulation. Access to the salt-secreting gland was gained by removal of an eye. Thereafter, the methods of Dolensek (1971) were followed.

Tissues for histological examination were fixed in $10 \%$ neutral buffered formalin (NBF) or formol sublimate, paraffin embedded, sectioned at $6 \mu \mathrm{m}$ and routinely stained with haematoxylin and eosin ( $H \& E$ ). Special stains included Gram-stain Twort for bacteria; Ziehl Neelsen for acid-fast organisms; periodic acid Schiff and silver methenamine for fungal hyphae; phloxin tartrazine for inclusion bodies; Martius scarlet blue and phosphotungstic acid and haematoxylin for fibrin; Dominici for eosinophils; toluidine blue for mast cells; Perl's prussian blue for iron; and von Kossa for calcium (Drury et al. 1967, Culling 1974). Blood films were stained by May Grünwald-Giemsa (Gurr 1973).

Both captive and wild turtles (Glazebrook \& Campbell 1990) were examined for the presence of pathogenic viruses, bacteria and fungi. Parasites were also collected from turtles regardless of whether or not they were associated with gross lesions

For viruses: samples of skin, heart, lung, liver and kidney were stored in liquid nitrogen for transport to the laboratory. Tissue suspensions $(10 \%)$ were prepared from thawed material with Ten Broeck tissue grinders using Eagle's basal medium (BME) containing antibiotics (penicillin $100 \mathrm{IU} \mathrm{ml}^{-1}$, streptomycin $200 \mu \mathrm{g}$ $\mathrm{ml}^{-1}$, Polymyxin B $40 \mathrm{IU} \mathrm{ml} \mathrm{m}^{-1}$, Kanamycin $80 \mu \mathrm{g} \mathrm{ml}^{-1}$ and fungizone $4 \mu \mathrm{g} \mathrm{m} \mathrm{ml}^{-1}$ ) as diluent. It was found necessary to macerate skin beforehand. The suspensions were clarified by low speed centrifugation, resus- 


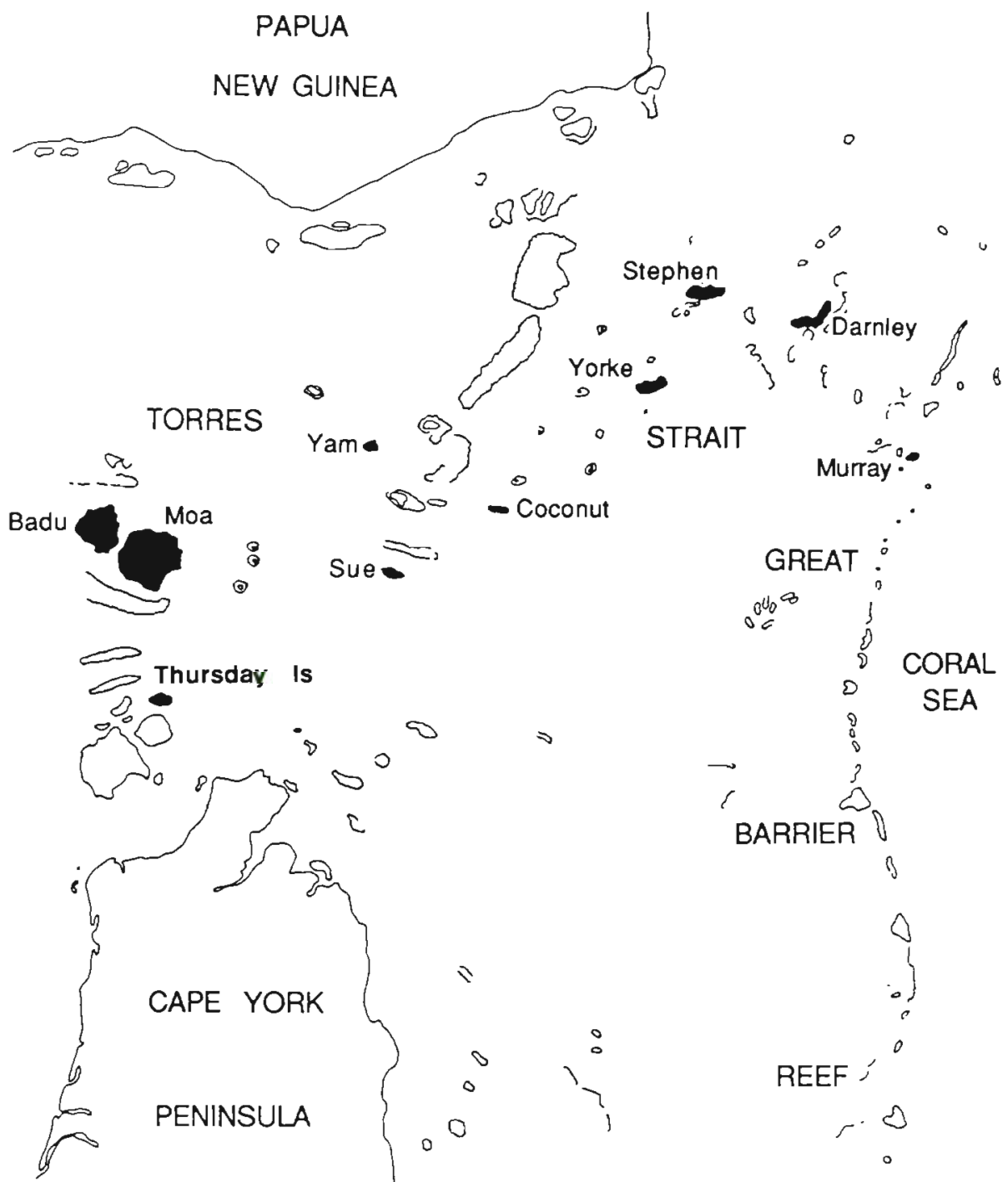

Fig. 1. Map of the Torres Strait showing location of farms and major green turtle rookeries pended in fresh medium and frozen and thawed 3 times. Final centrifugation was at $2200 \times g$ for $20 \mathrm{~min}$ and aliquots of the supernatant were absorbed to green turtle skin, heart and kidney cells for $1 \mathrm{~h}$ at $28^{\circ} \mathrm{C}$. Inoculated cultures were maintained with $\mathrm{BME}$ and antibiotics and $5 \%$ foetal calf serum (FCS) and kept in a $28^{\circ} \mathrm{C}$ incubator. In addition, scrapings from skin lesions were suspended in medium, chilled in a beaker of ice and ultrasonicated at peak amplitude ( $8 \mu$ peak to peak; M.S.E. Ltd, London, England). After freezing and thawing, a few drops were absorbed to turtle cells as before. Cells were passaged in a split ratio of $1: 2$.

Skin lesions were examined under the electron microscope and stained histological sections prepared by standard techniques. For negative staining, lesion scrapings were added to distilled water and placed directly on to grids. Vesicular fluid was applied without dilution. Both preparations were negatively stained with $2 \%$ phosphotungstic acid and examined under an electron microscope (Siemens Elmiskop 102).
For bacteria: material from gross lesions were cultured on a variety of selective and non-selective media viz nutrient agar and blood agar (Oxoid), trypticase soy agar (B.B.L.), seawater agar (Simidu \& Hasuo 1968), peptone beef extract glycogen agar (McCoy \& Seidler 1973) and RS medium (Shotts \& Rimler 1973) for Aeromonas hydrophila, Dubos medium (Difco) and Lowenstein-Jensen medium (Cowan \& Steel 1970) for Mycobacterium spp., and chitin agar (Skerman 1967) for chitinoclastic bacteria. To support organisms with an obligate salt requirement, all media contained $3 \%$ $\mathrm{NaCl}$. Slopes were preferred in the field. Refrigeration after inoculation was not always possible and frequently 10 to 14 d elapsed between inoculation and the first sub-culture. With few exceptions, cultures were attempted only from live, clinically affected turtles in both early and advanced stages of disease.

Inocula were obtained by sampling caseous material present in the nasal passages, oral cavity, trachea and salt-secreting gland with a sterile swab or by searing 
the exposed surface of lesions or organs under investigation with a heated scalpel blade and inserting a Pasteur pipette through the sterilised area. Blood was collected by heart puncture and, together with skin lesion material and peritoneal fluid, applied directly to media. For turtles with pitted shells, chips were taken from the borders of lesions.

In the laboratory, isolates were transferred to plated media (usually blood agar or trypticase soy agar) by the 16 streak dilution technique to separate the organisms present. Once a pure growth was obtained, a series of physical and biochemical tests was applied to identify the organism in question. All cultures were incubated at $25^{\circ} \mathrm{C}$ aerobically, although several tests e.g. Thornley's arginine, oxidation/fermentation of sugars required anaerobic conditions. Results were confirmed by the Queensland Department of Primary Industries Animal Health Laboratory, Townsville; Roche Pty Ltd, Sydney: and the Salmonella Reference Laboratory, Adelaide.

For fungi: slopes of Sabouraud's dextrose agar (SDA) or corn meal agar (CMA) were prepared for isolation attempts in the field. Clinical material was inoculated by breaking the surface of the agar with a sterile swab or Pasteur pipette.
All cultures experienced ambient temperatures (23 to $33^{\circ} \mathrm{C}$ ) during transport but were later maintained at $25^{\circ} \mathrm{C}$ (room temperature) in the laboratory. There, colonies were reestablished on plated media (SDA and CMA) and their morphology examined at 3 to $6 \mathrm{~d}$ intervals for 2 to $3 \mathrm{wk}$ after inoculation.

Microscopic characters viz diameter of hyphae, whether branched or unbranched and septate or nonseptate, and the method of reproduction of the fungus were determined by a wet mount preparation (Anon. 1964). Lactophenol cotton blue was used as a counterstain. Isolates were sent to the Animal Research Institute, Brisbane, for confirmation of the results obtained. Several strains were identified to the species level by the Commonwealth Mycological Institute at Kew in England.

For parasites: a routine search was made for internal and external parasites. The internal organs were first examined in situ. Prior to its removal, the alimentary tract was ligated at the level of the oesophagus and colon. This organ was opened longitudinally and approximate counts taken of free and attached worms present in the stomach, large and small intestines. Mucosal scrapings were also examined under a stereo

Table 2. Chelonia mydas and Eretmochelys imbricata. Systemic diseases of farmed turtles

\begin{tabular}{|c|c|c|c|}
\hline System & Diseases & $N$ & $\%$ \\
\hline \multicolumn{4}{|l|}{ Integumentary } \\
\hline Skin and appendages & Traumatic ulcerative dermatitis & 66 & 63.5 \\
\hline Sensory & Keratoconjunctivitis - ulcerative blepharitis & 9 & 8.6 \\
\hline \multirow[t]{3}{*}{ Skeletal } & Fibrous osteodystrophy & 2 & 1.9 \\
\hline & Osteomyelitis & 1 & 0.9 \\
\hline & Ulcerative shell disease & 2 & 1.9 \\
\hline Muscular & Cachetic myopathy & 40 & 38.0 \\
\hline \multicolumn{4}{|l|}{ Digestive } \\
\hline \multirow[t]{6}{*}{ Alimentary tract } & Ulcerative stomatitis & 23 & 22.1 \\
\hline & Gastritis-serositis syndrome & 15 & 14.4 \\
\hline & Gastro intestinal fluke infection & 14 & 9.9 \\
\hline & Necrotic enteritis & 1 & 0.9 \\
\hline & Perforative gastritis & 2 & 1.9 \\
\hline & Intestinal obstruction - faecal impaction & 4 & 3.8 \\
\hline Liver & Focal hepatitis & 1 & 0.9 \\
\hline \multicolumn{4}{|l|}{ Respiratory } \\
\hline Nasal passages & Obstructive rhinitis & 9 & 8.6 \\
\hline \multirow{2}{*}{ Lungs } & Bronchopneumonia & 12 & 11.5 \\
\hline & Focal pneumonia & 8 & 7.7 \\
\hline \multicolumn{4}{|l|}{ Cardio-vascular } \\
\hline Heart and major & Focal endocarditis - chronic arteritis & 5 & 4.8 \\
\hline associated yessels & Septicaemia - toxaemia & 5 & 4.8 \\
\hline \multicolumn{4}{|l|}{ Excretory } \\
\hline Bladder & Cystic calculus & 1 & 0.9 \\
\hline Salt secreting gland & Adenitis & 2 & 1.9 \\
\hline
\end{tabular}




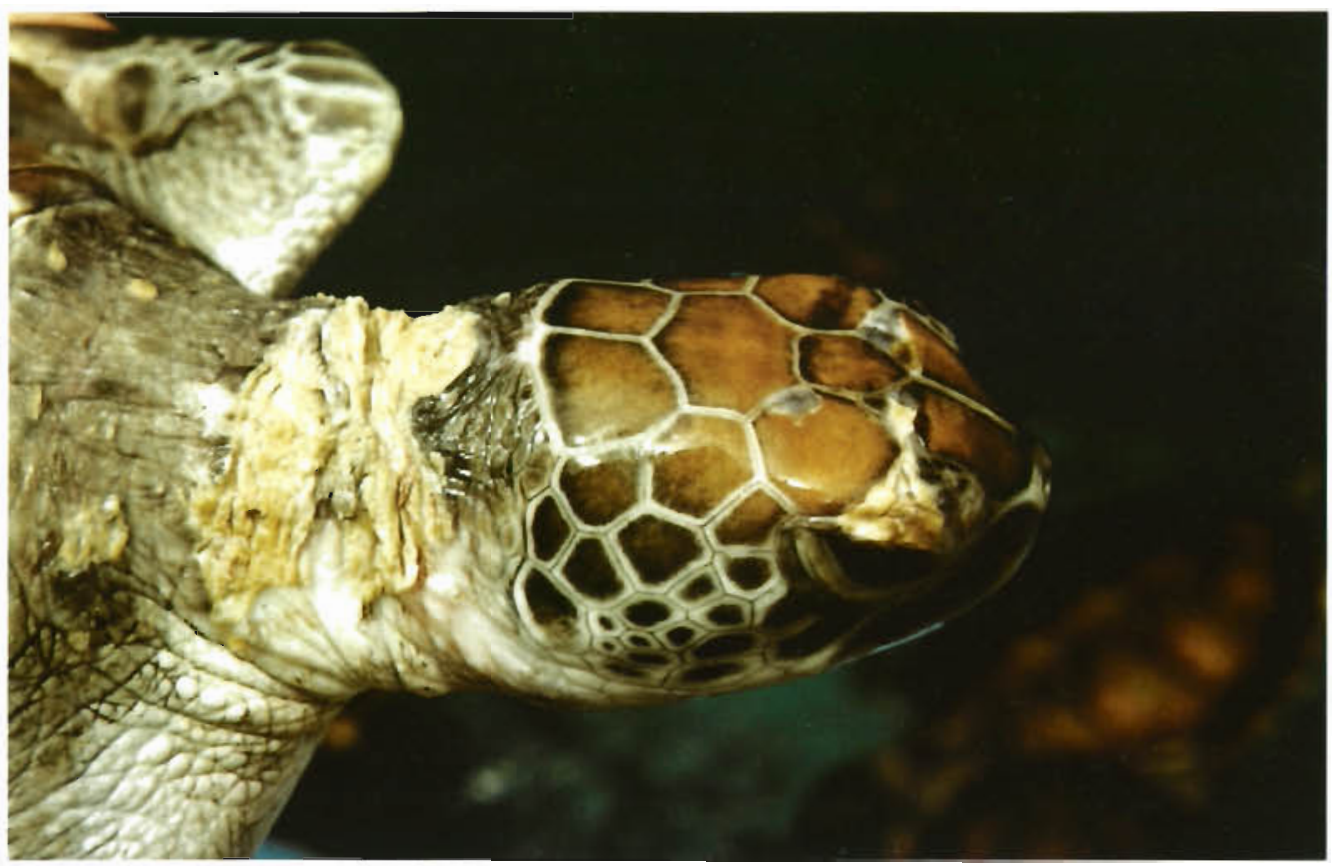

Fig. 2. Chelonia mydas Traumatic ulcerative dermatitis (biting): chronic lesion on the dorsum of the neck of a 3-yr-old turtle from Yorke Island

microscope. In addition, records were kept of the size and appearance of parasites and associated pathological changes.

Nematodes and cestodes were killed and fixed by immersion in hot $70 \%$ ethanol. Good specimens (obtained by dissection) were cleared in lactophenol (room temperature for 1 to $2 \mathrm{~d}$ ). Initially trematodes were fixed by placing them directly into $10 \% \mathrm{NBF}$. Later, a procedure recommended by Blair (1979 pers. comm.) was adopted: flukes were collected in a petri dish and killed by pouring near-boiling water on top of them, they were then covered with a filter paper soaked in seawater, and finally $10 \%$ NBF was added to the filter paper for fixation. For the study of their internal structures, flukes were stained with acetic acid alum carmine, cleared in clove oil and mounted in Canada balsam. A scanning electron microscope (ETEC Autoscan) was used to study fine surface details.

\section{RESULTS}

\section{Systemic diseases}

Systemic diseases of farmed turtles are given in Table 2. Ulcerative skin lesions (due to biting) were the most common sign of disease, occurring in $63.5 \%$ of turtles examined. Farmed turtles, particularly hatchlings, were severely affected (88\%), with multiple lesions ( 1 to $6 \mathrm{~mm}$ in diameter) on the tips and trailing edges of the flippers, tail and neck. Older turtles (juveniles and sub-adults) showed severe ulcerative lesions (up to $5 \mathrm{~cm}$ in diameter) on the dorsum of the neck (Fig. 2), flippers and tail.

Eye lesions took several forms: a yellow deposit on the cornea adjacent to the eyelids indicated keratoconjunctivitis. In some cases, complete erosion of the upper eyelid had occurred (ulcerative blepharitis), possibly due to external trauma followed by the invasion of secondary bacteria. These lesions were observed in $9 / 104(8.6 \%)$ of farmed turtles.

Diseases of the skeletal system were uncommon. Fibrous osteodystrophy was diagnosed in $2(1.9 \%)$ farmed turtles (Chelonia mydas) with enlarged, misshapen mandibles and curled carapaces that were soft on digital pressure. Radiography confirmed the diagnosis. Ulcerative shell disease was characterised by the appearance of dark, focal discolourations on the carapace of farmed turtles. These progressed into pits or ulcers 2 to $5 \mathrm{~mm}$ across.

Cachetic myopathy was indicated by generalised muscle wastage and sunken eyes. This condition was frequently observed in turtles suffering from other diseases viz traumatic ulcerative dermatitis, obstructive rhinitis-ulcerative stomatitis-bronchopneumonia, parasitic gastritis-serositis, heart fluke infestation and intestinal blockage; $38 \%(40 / 104)$ of farmed turtles were affected.

Ulcerative stomatitis was the most important bacterial disease after traumatic ulcerative dermatitis among farmed turtles (23/104 or $22.1 \%)$. The disease was manifested by the appearance of yellow, caseous material within the oral cavity of hatchlings 5 to $9 \mathrm{wk}$ old (Fig. 3). They also displayed open mouth breathing 
or dyspnoea. Together with traumatic ulcerative dermatitis, this condition was responsible for the death of $72.3 \%$ of hatchlings on Badu Island in 1979. Other islands recorded similar mortality rates.

On the single occasion when necrotic enteritis was diagnosed, yellow, caseous material was found adhering to a small section $(3 \mathrm{mr})$ of the large intestine. Sloughing of the mucosa was also evident. Because of the focal nature of the lesion it was thought that it may have been caused by a foreign body (now dislodged).

Larval nematodes of the genus Anisakis were responsible for a form of parasitic gastritic-serositis. Fresh sardines (spotted herring (Herkolotsichyts sp.) and hardyhead ( $F$. Atherinidae)], infested with these worms, were fed routinely to farmed turtles on Darnley and Míurray İsiands. The migration of larvae from the lumen of the gut to the pleuroperitoneal cavity resulted in a number of pathological changes viz ulceration of

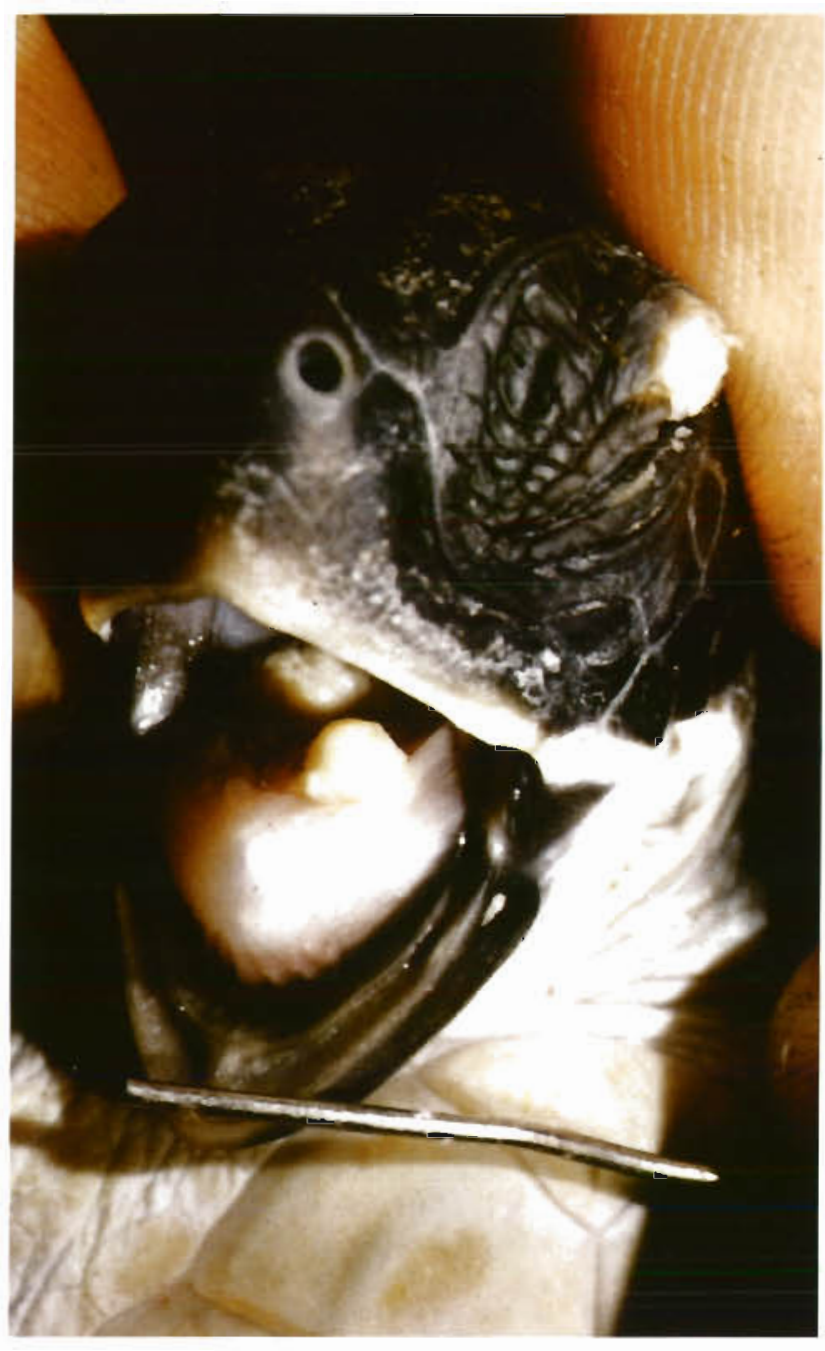

Fig. 3. Chelonia mydas. An 8-wk-old hatchling suffenng from ulcerative stomatitis. Caseous material has accumulated on the dorsum of the tongue

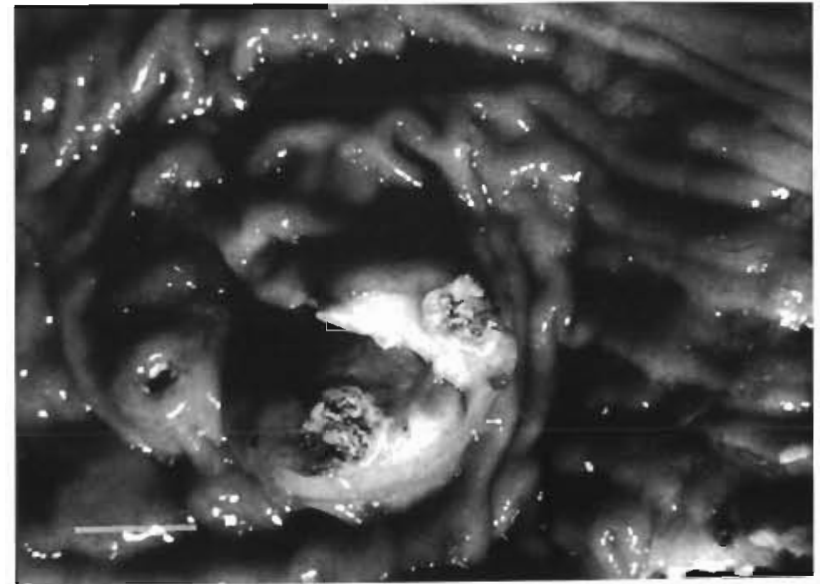

Fig. 4. Chelonia mydas. Gastric ulcers in a 3-yr-old turtle from Darnley Island, caused by the migration of third stage Anisakis sp. larvae. The sectioned lesion shows a central area of necrosis surrounded by an extensive fibrotic reaction. Scale bar $=1 \mathrm{~cm}$

the gastric and intestinal mucosa (Fig. 4) and visceral adhesions. This disease was confined to juvenile and sub-adult turtles from the 2 island mentioned and later Badu Island, following the transfer of turtle yearlings to that island for fattening.

Gastric and intestinal flukes were a feature of farmed turtles in all categories although they were most common in wild turtles (Glazebrook \& Campbell 1990). They were occasionally associated with petechial haemorrhages in the gastric mucosa.

On Yorke Island loose roofing material (coconut palm fronds) was mistaken for food and eventually pierced the stomach wall causing perforative gastritis. A fresh water weed, Salvinia molesta, offered to farmed turtles at the same farm caused severe constipation. Small, pale foci $(<1 \mathrm{~mm})$ in the liver of a farmed turtle from Yorke Island were associated with an enteric pathogen Salmonella enteritidis.

Obstructive rhinitis usually occurred in association with ulcerative stomatitis, although not as frequently as that condition $(9 / 104$ or $8.6 \%$ and $23 / 104$ or $22.1 \%$ cases in farmed turtles respectively). It seemed likely that this syndrome arose during the active expulsion of water by the hyoid apparatus on surfacing. Yellow, caseous material was lodged in nasal passages thereby inhibiting normal respiration. Only rarely were both nares occluded. Bronchopneumonia was a further complication, but was restricted to turtles aged between 2 and 8 mo which had previously suffered from ulcerative stomatitis. Here again, the disease was confined to farmed turtles with the exception of a single case from Magnetic Island (Glazebrook \& Campbell 1990). Turtles with this condition usually displayed a definite list (up to $40^{\circ}$ ) to one side. Focal pneumonia was less frequently encountered in 8/104 (7.7\%) farmed turtles, with opportunistic fungi (Paecilomyces sp.) being 
mainly responsible. Lesions were situated in the apical portion of the lung and were 3 to $8 \mathrm{~mm}$ in diameter.

The presence of heart flukes was diagnosed histologically in 5 farmed turtles eggs being detected in tissues removed at post mortem. Only those with a curved carapace length (CCL) of $>18 \mathrm{~cm}$ were affected. Clinical signs included lethargy, sunken eyes, muscular atrophy and plastron shrinkage. Farmed turtles were also anorectic.

A calculus $(3 \mathrm{~cm})$ was removed from the urinary bladder of a juvenile farmed turtle from Yorke Island and an infection of the salt-secreting gland was diagnosed in 2 other turtles from the same island.

To summarise, most systemic diseases were of an infectious nature, although poor nutrition and accidental deaths also contributed.

\section{Non-systemic diseases}

Table 3 lists diseases of environmental and genetic origin. These conditions appear not to have originated in any particular system. An estimated 20 farmed turtles on Yam Island died when seawater from a nearby sandflat was pumped on top of them at low tide on a very hot day in January 1979. Lordosis was noticed in 2 hatchlings intended for the farm on Yorke Island. They were from different clutches and had come from Bramble Cay. The curvature of the spine was maintained throughout life. Albinism was a rare phenomenon; a single hatchling from a clutch deposited on Bramble Cay during the 1978/1979 nesting season showed a complete lack of skin pigmentation and a much reduced caruncle. This turtle failed to emerge and was discovered during a routine check for infertile eggs. Another genetic defect (mandibular microagnathia) was detected in a hatching flown to Townsville from the Torres Strait for experimental studies. Although

Table 3. Chelonia mydas and Eretmochelys imbricata. Nonsystemic diseases of farmed turtles

\begin{tabular}{|lrr|}
\hline Disease & $\mathrm{N}$ & $\%$ \\
\hline Environmental & & \\
$\quad$ Hyperthermia & 30 & 28.8 \\
$\quad$ Lordosis & 2 & 1.9 \\
$\quad$ Kyphosis & 1 & 0.9 \\
Genetic & & \\
$\quad$ Albinism & 1 & 0.9 \\
$\quad$ Microagnathia (mandibular) & 1 & 0.9 \\
Other & & \\
$\quad$ Acute enteritis & & \\
$\quad$ (nitrate and diesel fuel & 4 & 3.8 \\
$\quad$ poisoning) & & \\
\hline
\end{tabular}

able to emerge, this specimen could not feed and died within $12 \mathrm{~d}$.

Owing to logistic difficulties turtles which died from hyperthermia were not examined.

Spinal abnormalities (lordosis and kyphosis) were encountered, but did not appear to affect the long-term survival of turtles in the farm situation. The incidence of these diseases was low $(<0.1 \%)$. Genetic defects had more serious ramifications, especially when vision (monopthalmia) and feeding (mandibular microagnathia) were affected. Hatchlings usually survived for only 3 to $5 \mathrm{~d}$.

\section{Bacterial diseases}

A range of bacteria was isolated from lesions in farmed turtles. They included organisms considered to be potentially pathogenic (Table 4 and 5) and a number of saprophytes.

Gram-negative bacteria were strongly represented; in particular Vibrio alginolyticus, Aeromonas hydrophila, Pseudomonas fluorescens, $P$. aeruginosa and Flavobacterium sp. $V$. alginolyticus and Flavobacterium sp. occurred in green and some hawksbill turtles. Coliforms viz Salmonella enteritidis, Arizona hinshairi and $\mathrm{H}_{2} \mathrm{~S}+$ ve Escherichia coli were isolated infrequently.

Table 4. Chelonia mydas and Eretmochelys imbricata. Bacterial diseases of farmed turtles. Values in parentheses indicate no. affected

\begin{tabular}{|c|c|c|}
\hline Disease & Species affected & $\%$ \\
\hline $\begin{array}{l}\text { Vibriosis } \\
\text { (Vibrio alginolyticus) }\end{array}$ & $\begin{array}{l}\text { C. mydas }(10) \\
\text { E. imbricata (1) }\end{array}$ & 10.6 \\
\hline $\begin{array}{l}\text { Aeromoniasis } \\
\text { (Aeromonas hydrophila) }\end{array}$ & C. mydas $(10)$ & 9.6 \\
\hline $\begin{array}{l}\text { Pseudomoniasis } \\
\text { (Pseudomonas fluorescens, } \\
\text { Ps. aeruginosa, or non- } \\
\text { oxidative pseudomonads) }\end{array}$ & C. mydas (15) & 14.4 \\
\hline $\begin{array}{l}\text { Cryptophagiasis } \\
\text { (Cytophaga-Flavo- } \\
\text { bacterium sp. infection) }\end{array}$ & $\begin{array}{l}\text { C. mydas }(10) \\
\text { E. imbricata (1) }\end{array}$ & 10.6 \\
\hline $\begin{array}{l}\text { Tuberculosis } \\
\text { (Mycobacterium sp.) }\end{array}$ & C. mydas (2) & 1.9 \\
\hline $\begin{array}{l}\text { Salmonellosis } \\
\text { (Salmonella enteritidis) }\end{array}$ & C. mydas (1) & 0.8 \\
\hline $\begin{array}{l}\text { Coliforms } \\
\text { (E. coli } \mathrm{H}_{2} \mathrm{~S}+\mathrm{ve} \\
\text { Arizona hinshain) }\end{array}$ & C. mydas (2) & 1.9 \\
\hline $\begin{array}{l}\text { Alpha Streptococcosis } \\
\text { (alpha-haemolytic } \\
\text { Streptococcosis) }\end{array}$ & C. mydas (2) & 1.9 \\
\hline
\end{tabular}


Table 5. Chelonia mydas and Eretmochelys imbricata. Bacterial diseases of farmed turtles; prevalence of known pathogens: (Va) Vibro alginolyticus; (Ah) Aeromonas hydrophila; (PS sp.) Pseudomonas sp.; (C-F sp.) Cytophaga-Flavobacterium sp.; (M sp.) Mycobacterium sp.; (Se) Salmonella enteritidis; (EC/Ah) Escherichia coli/Arizona hinshairi; $(\alpha$-St) $\alpha$-haemolytic streptococci. Values are no. times isolated/no. cases culturally examined

\begin{tabular}{|c|c|c|c|c|c|c|c|c|}
\hline Disease & $V a$ & Ah & Ps sp. & $C-F \mathrm{sp}$ & $M$ sp. & $S e$ & Ec/Ah & $\alpha-S t$ \\
\hline Traumatic ulcerative dermatitis & $3 / 6$ & $1 / 6$ & $2 / 6$ & $4 / 6$ & - & - & - & - \\
\hline Ulcerative stomatitis & $1 / 5$ & $3 / 5$ & $3 / 5$ & $2 / 5$ & - & - & - & $1 / 5$ \\
\hline Obstructive rhinitis & $1 / 3$ & $1 / 3$ & $1 / 3$ & $1 / 3$ & - & - & - & - \\
\hline Bronchopneumonia & $5 / 13$ & $4 / 13$ & $3 / 13$ & $3 / 13$ & - & - & $2 / 13$ & - \\
\hline Focal pneumonia & - & - & - & - & $2 / 8$ & - & - & - \\
\hline Focal hepatitis & - & - & - & - & - & $1 / 1$ & - & - \\
\hline Keratoconjunctivitis-ulcerative blepharitis & - & - & $2 / 9$ & $3 / 9$ & - & - & - & - \\
\hline Adenitis (salt-secreting gland infection) & - & - & $2 / 2$ & - & - & - & - & - \\
\hline 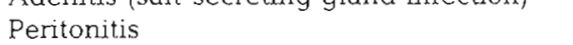 & - & - & $2 / 2$ & - & - & - & - & - \\
\hline Septicaemia-toxaemia & $1 / 3$ & $1 / 3$ & $1 / 3$ & - & - & - & - & - \\
\hline Ulcerative shell disedse & $1 / 2$ & - & $1 / 2$ & - & - & - & - & - \\
\hline Osteomyelitis & $1 / 1$ & - & $1 / 1$ & $1 / 1$ & - & - & - & - \\
\hline
\end{tabular}

Gram-positive bacteria appeared to play a less significant role in the pathogenesis of farm diseases. Two cases of pulmonary tuberculosis were diagnosed histologically.

Various saprophytes viz Moraxella sp., Proteus sp., Bacillus sp. and Micrococcus sp. formed part of the normal skin flora and were also found in the oral cavity and trachea.

Four organisms viz Vibrio alginolyticus, Aeromonas hydrophila, Pseudomonas sp. and Flavobacterium sp. were isolated repeatedly from lesions associated with traumatic ulcerative dermatitis, ulcerative stomatitis, obstructive rhinitis and bronchopneumonia (Table 5). There appeared to be a definite relationship between these organisms and the above diseases. As major lesions were exposed to the external environment, i.e. tank or basin water, mixed cultures were usually obtained. All conditions were largely confined to hatchlings and juveniles.

Salmonellosis (Salmonella enteritidis) was diagnosed only once, from a juvenile turtle on Yorke Island. Microscopic examination of the liver revelaed the presence of bacteria surrounded by a focal infiltrate of lymphocytes and macrophages.

Pseudomonas aeruginosa and Flavobacterium sp. were isolated from ulcerative lesions on the eyelids, where they acted as opportunistic pathogens invading tissues previously damaged by trauma. This type of lesion was common in juvenile turtles. Pseudomonas aeruginosa was also isolated in pure culture from abscesses in the salt-secreting gland and peritoneal wall. Once again, juvenile turtles were affected.

A form of ulcerative shell disease was also observed in farmed turtles. Vibrio alginolyticus and Pseudomonas sp. were isolated from lesions on the carapace of turtles from Sue Island and shown to have chitinase activity. The same organisms were recovered from a deep, penetrating ulcer wound on a flipper of a turtle from Yorke Island.

\section{Fungal diseases}

Fungal diseases are presented in Table 6. Evidence was obtained that certain fungi were pathogenic to green turtles under farm conditions. Paecilomyces sp. was cultured from focal, granulomatous lesions in the lungs of 2 juvenile turtles from Yorke Island. At the microscopic level, hyphae were seen in the central necrotic core of the lesion, surrounded by multinucleated giant cells. A similar histopathological picture was observed in another turtle from the same island; in this case no attempt was made to identify the causative organism(s). Other fungi viz Fusarium scirpi and Penicillium sp. were isolated from more diffuse lesions (cases of bronchopneumonia), but the absence of discrete foci of infection, i.e. focal granulomas suggested that they were contaminants.

\section{Parasitic diseases}

Parasitic diseases are listed in Table 7. Larval nematodes found in the gut and pleuroperitoneal cavity of farmed turtles were identified as Anisakis Type I (simplex or typica). They occurred in $15 / 104$ (14.4\%) of

Table 6. Chelonia mydas. Fungal diseases of farmed turties

\begin{tabular}{|lll|}
\hline Disease & $\mathrm{N}$ & $\%$ \\
\hline Focal pneumonia & & \\
Paecilomyces sp. & 2 & 1.9 \\
Causal organism not identified & 1 & 0.8 \\
\hline
\end{tabular}


Table 7 Chelonia mydas and Eretmochelys imbricata. Parasitic diseases of farmed turtles. No. each species affected in parentheses

\begin{tabular}{|llll|}
\hline Disease & Parasite & Species affected \\
\hline Gastritis-serositis syndrome & $\begin{array}{l}\text { Nematodes } \\
\text { (3rd stage Anisakis sp. larvae) }\end{array}$ & C. mydas (15) \\
Focal endocarditis with disseminated & $\begin{array}{l}\text { Trematodes } \\
\text { egg granulomas }\end{array}$ & Adult flukes not found & C. mydas (3) \\
Gastric and intestinal flukes & Trematodes & E. imbricata (1) \\
& Cricocephalus sp. & C. mydas (2) & \\
\hline
\end{tabular}

turtles examined and were confined to Darnley and Murray Islands. Yearlings were more heavily infested than juveniles. A spot check performed on sardines used as food on Darnley Island revealed than 30/40 $(75 \%)$ were carriers. Turtles infected with larvae rarely showed acute clinical signs ( 1 died from nitrate poisoning), but appeared weak and emaciated and fed infrequently. In addition to the more obvious signs viz cachetic myopathy and plastron shrinkage, an emaciated state was indicated by the skin which was tough and dry and had a tendency to peel. Two turtles also had a persistent list to one side which they attempted to correct using the front flippers. When the pleuroperitoneal cavity was first opened, migrating and encysted larvae were immediately apparent. Migrating larvae were seen penetrating the gut wall and passing through the mesentery to nearby organs (lungs, liver and spleen) and the adjacent peritoneum. Adhesions had developed between the stomach and peritoneal wall and occasionally the lungs were also involved with 2 specimens showing a list to one side. Encysted larvae had localised in the peritoneal wall and liver capsule. Turtles with low grade infections had several larvae encysted in the peritoneal wall. Parasitic cysts consisted of collections of tightly coiled larvae surrounded by a wall of fibrous tissue. Gastric and intestinal ulcers (Fig. 4) were a consistent pathological feature of the disease and were the direct result of larvae migrating from the lumen of the gut to the body cavity. They took the form of hard, caseous nodules up to $2 \mathrm{~cm}$ in diameter, raised above the surface of the mucosa. Larvae often protruded from the centre of these nodules into the gastric and intestinal lumen. Microscopically the lesions appeared as a central necrotic area surrounded by a ring of Langhan's giant cells and accompanied by an infiltrate of eosinophils and mononuclear cells. Bacteria had also invaded the gut wall along with larvae to produce a coagulative form of necrosis.

Trematode eggs, originating from flukes in the cardiovascular system, were seen in the liver, spleen and intestinal wall of yearlings from Yam Island and Yorke Island. In sections stained with $\mathrm{H} \& \mathrm{E}$, they appeared as yellow, hyalinised bodies, fusiform in shape and with a terminal spine, measuring up to $210 \times 40 \mu \mathrm{m}$. When sectioned obliquely many eggs had ruptured, leaving only fragments behind. The eggs were surrounded by a syncitium of Langhan's giant cells and in the spleen there was marked hypertrophy of arterial walls. A single adult fluke was found in the fascia between bundles of skeletal muscle fibres in a hawksbill turtle but was not associated with pathological change.

In contrast, flukes removed from the stomach and small intestine of yearlings from Badu Island were identified as belonging to the Genus Cricocephalus. Several flukes were in an engorged state and although the number per turtle ranged from 8 to 15 , they were not associated with gross lesions.

\section{Nutritional diseases}

Nutritional diseases are given in Table 8 . Cachetic myopathy appeared in conjunction with other diseases and persisted in severely debilitated turtles. Those most likely to be affected were suffering from an acute septicaemia/toxaemia or had a heavy parasitic burden. Obstruction of the gastrointestinal tract (due to a foreign body or incorrect diet) also predisposed turtles to the disease. Farmed turtles with this condition were anorectic and lethargic for several weeks prior to death. In extreme cases, they floated motionless on the surface of the water and were continually attacked by other turtles.

One case of fibrous osteodystophy due to nutritional secondary hyperparathyroidism was diagnosed. The affected turtle was 8 mo old and had been maintained on a diet of raw fish. In addition to the gross pathological features already mentioned, more subtle changes accurred elsewhere in the skeletal system. When dissected, the long bones were soft and spongy and their overall dimensions were larger than normal. The parathyroid glands were enlarged. Microscopically, resorption of bone was evident below the epiphyseal plate and some fibrous replacement had occurred.

During a visit to Yorke Island in September 1977 several farmed turtles were observed with a blocked 
Table 8. Chelonia mydas and Eretmochelys imbricata. Nutritional diseases of farmed turtles. No. each species affected in parentheses

\begin{tabular}{|llll|}
\hline Disease & Probable cause & Species affected \\
\hline Cachectic myopathy & Concurrent disease & C. mydas (39) & E. imbricata (1) \\
Fibrous osteodystrophy & & C. mydas (2) & 38.5 \\
Intestinal blockage - faecal impaction & Dietary Ca:P imbalance & C. mydas (2) & 1.9 \\
& palm frond material & C. mydas (1) & 0.8 \\
Cystic calculus & Dietary Ca:P imbalance & & \\
\hline
\end{tabular}

Table 9. Chelonia mydas. Other diseases of farmed turtles. No. each species affected in parentheses

\begin{tabular}{|llll|}
\hline Disease & Suspected aetiology & Species affected & $\%$ \\
\hline Acute enteritis & Nitrate poisoning (Tridax procumbens) & C mydas (2) & 1.8 \\
& Diesel fuel poisoning & C. mydas (1) & 0.9 \\
\hline
\end{tabular}

cloaca. The offending material was removed using a pair of forceps and identified as Salvinia molesta, an introduced weed which had been offered to the turtles by farmers. Apparently, this plant could not be properly digested by green turtles and was therefore unsuitable as a dietary supplement.

\section{Other diseases}

Other diseases are listed in Table 9. Losses due to accidental poisoning were reported from Darnley Island and Yorke Island. When wild daisies (Tridax procumbens) were fed to a group of 9 turtles on Darnley Island they became very distressed, swimming about frantically and crashing into the side of the tank. A mortality rate of $100 \%$ was recorded within a matter of hours. At autopsy, sectioning of the gut revealed inflammation of the gastric and intestinal mucosa and undigested plant material in the lumen. Microscopically, the intestinal villi showed severe degeneration as did the epithelium of the renal tubules and urinary bladder.

A toxic incident also occurred on Yorke Island when turtles were fed fish contaminated with diesel fuel. The day before a drum had leaked onto the floor of the fishing dory during rough weather and as a result, 30 turtles died overnight. One of the turtles examined showed necrosis of the gastric epithelium and intestine as well as marked pulmonary oedema.

\section{DISCUSSION}

Disease and management problems in the now discontinued Torres Strait turtle farms are emphasised by the present study. A range of infections and non-infectious diseases occurred on island farms. Ulcerative dermatitis caused by biting was almost universal; bacterial diseases of the oral cavity and parasitic infections of the stomach and cardiovascular systems were also prevalent in some locations. Nutritional disorders including secondary cachectic myopathy occurred frequently.

As in other species, intensive farming methods were predisposed to a myriad of diseases especially where management procedures were not refined and where methods of disease control were lacking.

Following the establishment of the world's first green turtle farm on Grand Cayman Island in 1968, a series of papers appeared in the literature (Rebell et al. 1975 , Leibovitz et al. 1978, Jacobson et al. 1979) describing diseases which had caused significant losses during the first few years of operation. Lebrun (1975) and Reme (1980) also mentioned 3 diseases which were present on the farm on Reunion Island, off the coast of Madagascar. Because of the economic importance of farmed turtles, it was essential to investigate disease outbreaks as soon as they occurred to determine their cause and an effective method of treatment (Haines \& Kleese 1977). However, at both locations, overall disease surveys have yet to be undertaken.

Bacterial diseases were by far the most important in farmed turtles. Two of the diseases listed in Table 5 viz traumatic ulcerative dermatitis and ulcerative stomatitis were associated with high morbidity and mortality rates, particularly in hatchlings. This finding suggested that conditions on the Torres Strait farms between 1977 and 1979 favoured the build up of bacteria viz Vibrio alginolyticus and Aeromonas hydrophila which were later shown to be pathogenic to green turtles. The wide 
range of organisms isolated (Table 5) meant that the immune system of the turtle had to cope with repeated and diverse challenges. Further, the very nature of the diseases encountered e.g. traumatic ulcerative dermatitis, indicated an invasive process. In support of this argument, many of the organisms isolated from gross lesions were also recovered from the same sites in healthy turtles, as well as the surrounding water. It was clear they were behaving as opportunistic pathogens.

Skin lesions due to biting (traumatic ulcerative dermatitis) were the most obvious sign of disease in farmed turtles on the islands visited. All age groups, i.e hatchlings, juveniles and yearlings were affected. Two of the organisms isolated from lesion material viz Vibrio alginolyticus and Flavobacterium sp. are regarded as normal inhabitants of seawater (Roberts 1978). Aeromonas hydrophila has long been recognised as a pathogen of reptiles (Reichenbach-Klinke \& Elkan 1965), while Pseudomonas sp. is more likely to be a skin contaminant. Reme (1980) noted aggression between green turtles in overcrowded tanks on Reunion Island, but did not fully realise the importance of this behaviour. No mention was made of biting although 'wounds' were present on the neck and hind flippers. Instead, he claimed that a herpes virus (after Rebell et al. 1975) was primarily responsible for the lesions. The herpes virus lesions described by Rebell et al. (1975) in mariculture-reared turtles on Grand Cayman Island were almost universal in 7 to 12 -wk-old hatchlings but had disappeared by the time they were 12-mo-old (Haines 1978). In contrast, lesions due to biting were present in yearlings ( 1 to 5 -yr-olds) on all farms in the Torres Strait. No evidence of virus infection was obtained either by culture or histopathology.

In terms of morbidity and mortality, ulcerative stomatitis was the most important disease of farmed turtles. The morbidity rate was lower than that for traumatic ulcerative dermatitis $(80$ to $90 \%$ compared with almost $100 \%$ ), but the mortality rate was noticeably higher (up to $40 \%$ ). This disease was part of a complex which included obstructive rhinitis and pneumonia. The upper and lower respiratory tracts became involved when caseous material was dislodged from the oral cavity. The same 4 organisms that were isolated from ulcerative skin lesions viz Vibrio alginolyticus, Aeromonas hydrophila, Pseudomonas sp. and Flavobacterium sp. recurred in the oral cavity, nasal passages and trachea (Table 5). Reme (1980) had earlier observed flagellated protozoans in smears from the oral cavity of turtles on Reunion Island, but failed to establish their pathogenicity.

More than any other organism, Aeromonas hydrophila has been implicated as the cause of ulcerative stomatitis in reptiles (Page 1966, Marcus 1968). However, this is the first time it has been isolated from green turtles with 'canker'. It is difficult to comment on the possible significance of Pseudomonas sp. in this disease (Table 5), although Wallach (1969) considered $P$. aeruginosa and $P$. fluorescens to be important in other reptiles. Flavobacterium sp. is a normal inhabitant of seawater and rarely becomes pathogenic.

Obstructive rhinitis has not been reported before in green turtles. As a complication of ulcerative stomatitis, it is not surprising that Vibrio alginolyticus, Aeromonas hydrophila, Pseudomonas sp. and Flavobacterium sp. were isolated from plugs of caseous material lodged inside the nasal passages. In contrast to the work of Reme (1980), a flagellated protozoan was not seen in the upper respiratory tract of farmed turtles.

Tuberculosis has been reported only once before in green turtles; in laboratory-reared specimens in Hawaii (Brock et al. 1976). In the present study, repeated attempts to isolate Mycobacterium spp. from focal lung lesions were unsuccessful, despite the use of specialised media (Dubos, Lowenstein-Jensen). Accordingly, a diagnosis was based on the presence of clumps of acid-fast bacilli in the centre of granulomatous lesions. Focal and diffuse lymphocytic infiltrates were seen in the liver of a turtle infected with Salmonella enteritidis. Keymer et al. (1968) had previously isolated $S$. regent from the intestinal contents of a Pacific hawksbill turtle with colitis, but the organism could not be isolated from the liver. The lesions associated with keratoconjunctivitis-ulcerative blepharitis in farmed turtles (Chelonia mydas only) in many ways resembled those described by Witham (1975) in greens and loggerheads. They first appeared on the superior eyelid (unilateral or bilateral) and spread to involve other tissues e.g. the orbit of the eye and top of the skull. Organisms isolated from these lesions viz Pseudomonas sp. and Flavobacterium sp. were also recovered from lesions on the front and rear flippers and neck (traumatic ulcerative dermatitis).

The salt-secreting gland in marine reptiles (SchmidtNielsen 1959) serves to regulate the concentration of $\mathrm{Na}^{+}, \mathrm{K}^{+}$and $\mathrm{Cl}^{-}$ions in the blood. On Yorke Island, bacterial infections resulted from the removal of 'foreign material' from the main excretory duct which opens into the posterior orbit. Although well intentioned, this procedure involved the use of forceps which introduced bacteria (Pseudomonas sp.) and led to infection. In farmed turtles, peritonitis was usually linked with anisakiasis. When larval nematodes penetrated the gut wall they carried bacteria (Pseudomonas sp.) with them. With regard to septicaemia-toxaemia, 2 of the 3 organisms isolated from heart blood were capable of producing powerful toxins (Roberts 1978). Ulcerative shell disease (Wallach 1975) has not been recorded before in sea turtles, captive or wild. The isolation of Vibrio alginolyticus and Pseudomonas $\mathrm{sp}$. 
from shell lesions in farmed turtles suggested that these organisms took the place of Beneckea chitinovora in a marine environment.

Focal pneumonia (Table 5) was diagnosed infrequently in farmed turtles (3/104). Jacobson et al. (1979) gave the impression that this condition was more common in mariculture-reared turtles, when they reported 29 cases from Grand Cayman Island. Paecilomyces sp. was the organism implicated in the Torres Strait. $P$. lilacinus has been isolated on several occasions from the lungs of green turtles (Austwick \& Keymer 1981) and Paecilomyces sp. and Sporotrichum sp. from the loggerhead turtle (Jacobson et al. 1979).

The diagnosis of a parasitic gastritis-serositis syndrome, i.e. anisakiasis in farmed turtles, conforms to the work of Carr \& Main (1973) and Rodgers \& Burke (1982) who discovered Anisakis Type I larvae in the body cavities of turtles from Murray Island. In the present survey, all 15 turtles suffering from the disease (Table 7) were from Darnley or Murray Island. They acted as paratenic hosts for third stage larvae unable to complete their life cycle when confined to the tissues of a cold-blooded animal. This disease has not been reported elsewhere.

Leared (1862) was the first to observe trematode eggs in the tissues of a wild green turtle. Fluke eggs were seen in the liver, spleen and intestine of farmed turtles from the Torres Strait, whereas Greiner et al. (1980) found them only in the kidneys of mariculture-reared turtles. Because of the absence of marine gastropods from their tanks, farmed turtles had only grade infestations. The infective stage, i.e. fork-tailed cercariae, were probably pumped into tanks from the nearby sea.

Blair (pers. comm.) found gastro-intestinal flukes belonging to the Genus Cricocephalus in farmed turtles on Badu Island, while in the present survey they occurred in 2 turtles which had been transported to Badu Island from Darnley Island.

Cowan (1968), Frye (1973) and Burton (1978) observed the chronic loss of weight which accompanied prolonged disease in reptiles. However, up till now, cachetic myopathy has not been reported in farmed turtles. The diet of turtles on Yorke Island (Ca:P $=1: 44$ in Spanish mackerel) favoured the development of fibrous osteodystrophy. Intestinal obstruction and faecal impaction were also dietary related. The only other incident of poisoning in farmed turtles was by Reme (1980) who suspected 'Rodenticide' had been used in foul play on Reunion Island.

Acknowledgements. We thank Associate Professor R. H. Johnson for his helpful suggestions during the survey period. Mr L. Reilly prepared histological sections and Mr R. Yeldham assisted with photography. Ms A. Thomas of the Queensland Department of Primary Industries and Dr D. Blair of the School of Biological Sciences, James Cook University, identified unusual marine bacteria and trematodes respectively. Dr J. Parmenter of the Capricornia College of Advanced Education and $\mathrm{Mr} \mathrm{C}$. Limpus of the Queensland National Parks and Wildlife Service provided valuable assistance in the field. The staff of Applied Biology Fty Ltd (a statutory company of the Commonwealth of Australia) gave logistic and financial support. The senior author is particularly indebted to $M r D$. Mosby of the Yorke Island Research Station for collaborative work with farmed turtles.

\section{LITERATURE CITED}

Anon. (1964). Laboratory Procedures in Clinical Mycology. Department of the Army Technical Manual TMB-277-8). Headquarters, Department of the Army, Washington, D.C. Austwick, P. K. C., Keymer, I. F. (1981). Fungi and Actinomycetes. In: Cooper, J. E. (ed.) Diseases of the Reptilia, Vol, 1. Academic Press, London, p. 120

Blair, D. (1979). A study of the helminth parasites of sea turtles in Quccrsland. Applied Ecology Pty Ltd., Canberra

Brock, J. A., Nakamura, R. M., Miyahara, A. Y., Chang, E. M. L. (1976). Tuberculosis in Pacific green sea turtles, Chelonia mydas. Trans. Am. Fish. Soc. 4: 654-656

Burton, J. D. (1978). Management and diseases of reptiles in captivity. Fauna course ${ }_{i}$ Part B. Post-graduate committee Veterinary Science, University of Sydney. Proceedings No. 36 of Course for Veterinarians, p. 247-270

Carr, A. F., Main, A. R. (1973). Turtle farming project in Northern Australia. Report on an inquiry into ecological implications of a turtle farming project. Union Offset Pty Ltd, Canberra

Cowan, D. F. (1968). Diseases of captive reptiles. J. Am. Vet. Med. Ass. 153: 848-859

Cowan, S. T., Steel, K. J. (1970). Manual for the identification of medical bacteria. Cambridge University Press, Cambridge, London

Culling, C. F. A. (1974). Handbook of histopathological and histochemical techniques. 3rd edn. Butterworth \& Co. London

Dolensek, E. P. (1971). Necropsy techniques in reptiles. J. Am. Vet. Med. Ass. 159: 1616-1617

Dury, R. A. B., Wallington, E. A., Cameron, R. (1967). Carleton's histological technique. 4th edn. Oxford University Press, New York

Frye, F. L. (1973). Husbandry, medicine and surgery in captive reptiles. V. M. Publishing Inc., Bonner Springs, Kansas

Gandal, C. P. (1958). A practical method of obtaining blood from anaesthetized turtles by means of cardiac puncture. Zoologica, N.Y. 43: 93-94

Glazebrook, J. S., Campbell, R. S. F. (1990). A survey of the diseases of marine turtles in northern Australia. II Oceanarium-reared and wild turtles, Dis. aquat. Org. 9: 97-104

Greiner, E. C., Forrester, J. J., Jacobson, E. R. (1980). Helminths of mariculture-reared green turtles (Chelonia mydas mydas) from Grand Cayman. British West Indies. Proc. helminth. Soc. Wash. 47: 142-144

Gurr, E. (1973). Biological staining methods. Searle Diagnostic, England

Haines, H. (1978). A herpesvirus disease of green sea turtles in aquaculture. Marine Fisheries Review Paper No. 1294, 40 : $33-37$

Haines, H., Kleese, W. C. (1977). Effect of water temperature on a herpesvirus infection of sea turtles. Infection Immunity 15: 756-759 
Jacobson, E. R., Gaskin, J. M., Shields, R. P., White, R. H. (1979). Mycotic pneumonia in mariculture-reared green sea turtles. Am. Vet. Med. Ass. 175: 929-932

Keymer, I. F., Ridealgh, D., Fretwell, G. (1968). Salmonella regent: a new species associated with colitis in a Pacific hawksbill turtle (E. imbricata bissa). J. Path. Bact. 96: 215

Leared, A. (1862). Discription of a new parasite found in the heart of the edible turtle. Q. Jl microsc. Sci. 12: 168-170

Lebrun, G. (1975). Breeding on Reunion Island of young green turtles, Chelonia mydas (Linnaeus) 1758. Science and Fishing, Scientific and Technical Institute for Maritime Fishing 248: 1-25 (in French)

Leibovitz, L., Rebell, G., Boucher, G. C. (1978). Caryospora cheloniae sp: A coccidial pathogen of mariculture-reared green sea turtles (Chelonia mydas). J. Wildl. Dis. 14: $269-275$

Marcus, L. C. (1968). Diseases of snakes and turtles. Curr, vet. Ther. 111: 435-442

McCoy, R. H., Seidler, R. J. (1973). Potential pathogens in the environment: isolation, enumeration and identification of seven genera of intestinal bacteria associated with small green pet turtles. Appl. Microbiol. 25: 534-538

Page, L. A. (1966). Diseases and infections of snakes: a review. Bull. Wildl. Diss. Ass. 2: 111-125

Rebell, G., Rywlin, A., Haines, H. (1975). A herpesvirus-type agent associated with skin lesions of green sea turtles in Aquaculture. Am. J, vet. Res. 36 (8): 1221-1224

Reichenbach-Klinke, H., Elkan, E. (1965). Book III. Diseases of

Responsible Subject Editor: Professor P. Zwart, Utrecht, The Netherlands
Reptiles. The Principal Diseases of Lower Vertebrates. Academic Press, London

Reme, A. (1980). Quelques problèmes sanitaires et pathogiques dans l'elevage intensif de la tortue marine (Chelonia mydas L.) à la Réunion. Rev. Elev. Méd. Vet. Pays trop. 33 (2): 177-192

Roberts, R. J. (1978). Fish Pathology. Bailliere Tindall, London Rodgers, L. J., Burke, J. B. (1982). Gastric ulceration associated with larval nematodes. Anisakis type I in pen-reared green turtles from the Torres Strait. J. Wildl. Dis. 18: 41-46

Schmidt-Nielsen, K. (1959). Salt glands. Scient. Am. 200: 109-116

Shotts, E. B., Rimler, R. B. (1973). Medium for the isolation of Aeromonas hydrophila. Appl. Microbiol 26: 550-553

Simidu, U., Hasuo, K. (1968). An improved medium for the isolation of bacteria from marine fish. J. gen. Microbiol. 52 : 355-360

Skerman, V. B. D. (1967). A guide to the identification of the genera of bacteria. 2nd ed. Williams and Wilkins, Baltimore

Smith, L. S. D. (1977). Botulism, the organism, its toxins, the disease. C. C. Thomas, Illinois

Wallach, J. D. (1969). Medical care of reptiles. J. Am. Vet. Med. Ass. 155: 1017-1034

Wallach, J. D. (1975). The pathogenesis and aetiology of ulcerative shell diseases in turtles. J. zool. anim. Med. 6: $11-13$

Witham, R. (1975). Focal necrosis of the skin in tank reared turtles. J. Am. Vet. Med. Ass. 163: 656

Revised version accepted: June 22,1990 